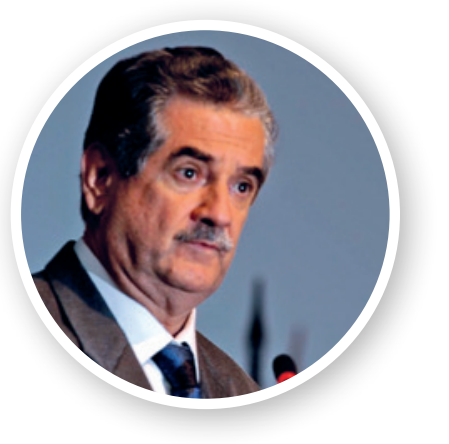

\title{
Professor Roberto Attilio Lima Santin (1938-2020)
}

Professor Roberto Attilio Lima Santin passed away peacefully on the morning of July 13, 2020. Born in the countryside of the state of Sao Paulo, he graduated from University of Sao Paulo at Ribeirao Preto. He entered residency in orthopedic surgery in the early 1960s at Santa Casa de Misericordia de Sao Paulo, where he later became a staff member. Prof. Santin was appointed chief of the Foot and Ankle Group on two different occasions. He was also president of several professional societies, such as the Brazilian Society of Orthopedics and Traumatology (SBOT), Paulista Association of Orthopedics and Traumatology, Brazilian Society of Orthopedic Trauma, and Brazilian Society of Limb Lengthening and Reconstruction (ASAMI), and was known for his ethical and peaceful attitude.

Prof. Santin's pioneering and consistent support for a single Latin American scientific journal for foot and ankle surgery led to its creation. He constantly sought opportunities for learning and teaching and found special joy in sharing his wide knowledge. Although he had a preference for foot and ankle surgery, his practice involved all areas of orthopedic surgery. His work combined simplicity in handling unique situations, devotion to helping those in need, elegance while performing operations, and cordiality in coexisting with different personalities. The remarkable characteristics of this beloved master have earned him wide recognition and admiration in the medical community. His ideas, advice, and his standing as physician and professor will always be remembered, and he will be dearly missed by those who had the honor and pleasure of his company.

\section{May God bless and comfort his family and friends in this time of grief. Rest in peace beloved teacher.}

\author{
MARCO TÚLIO COSTA \\ CHIEF OF THE FOOT AND ANKLE GROUP \\ OF SANTA CASA DE MISERICORDIA SAO \\ PAULO, SÃO PAULO, SP, BRAZIL
}

\author{
MARIA FERNANDA SILBER CAFFARO \\ DIRECTOR OF THE ORTHOPEDIC AND \\ TRAUMATOLOGY DEPARTMENT SANTA \\ CASA DE MISERICORDIA SAO PAULO,
}

SÃO PAULO, SP BRAZIL 